\title{
Weak and Strong Convergence Theorems for the Multiple-Set Split Equality Common Fixed-Point Problems of Demicontractive Mappings
}

\author{
Yaqin Wang, ${ }^{1}$ Tae-Hwa Kim, ${ }^{2}$ and Xiaoli Fang ${ }^{1}$ \\ ${ }^{1}$ Department of Mathematics, Shaoxing University, Shaoxing 312000, China \\ ${ }^{2}$ Department of Applied Mathematics, College of Natural Sciences, Pukyong National University, Busan 48513, Republic of Korea \\ Correspondence should be addressed to Tae-Hwa Kim; taehwa@pknu.ac.kr
}

Received 29 March 2017; Accepted 19 October 2017; Published 24 December 2017

Academic Editor: Xinguang Zhang

Copyright (c) 2017 Yaqin Wang et al. This is an open access article distributed under the Creative Commons Attribution License, which permits unrestricted use, distribution, and reproduction in any medium, provided the original work is properly cited.

We consider mixed parallel and cyclic iterative algorithms in this paper to solve the multiple-set split equality common fixed-point problem which is a generalization of the split equality problem and the split feasibility problem for the demicontractive mappings without prior knowledge of operator norms in real Hilbert spaces. Some weak and strong convergence results are established. The results obtained in this paper generalize and improve the recent ones announced by many others.

\section{Introduction}

For modeling inverse problems which arise from phase retrieval and in medical image reconstruction, in 1994, Censor and Elfving [1] firstly introduced the following split feasibility problem (SFP) in finite-dimensional Hilbert spaces.

Let $C$ and $Q$ be nonempty closed convex sets of the Hilbert spaces $H_{1}$ and $H_{2}$, respectively, and let $A: H_{1} \rightarrow H_{2}$ be a bounded linear operator. The split feasibility problem (SFP) is formulated to

$$
\text { find } x^{*} \in C \text { such that } A x^{*} \in Q \text {. }
$$

It has been found that the SFP can be used in many areas such as image restoration, computer tomograph, and radiation therapy treatment planning. Some methods have been proposed to solve split feasibility problems; see, for instance, [2-5].

Assuming that the SFP (1) has a solution, it is not hard to see that

$$
x^{*}=P_{C}\left(I-\gamma A^{*}\left(I-P_{\mathrm{Q}}\right) A\right) x^{*},
$$

where $P_{\mathrm{C}}$ and $P_{\mathrm{Q}}$ are the metric projections from $H_{1}$ onto $C$ and from $H_{2}$ onto $Q$, respectively, $\gamma$ is a positive constant, and $A^{*}$ denotes the adjoint of $A$. This implies that SFP can be solved by using fixed-point algorithms.

In 2013, Moudafi and Al-Shemas [6] introduced the following new split feasibility problem, which is called the split equality fixed-point problem (SEFP). Let $H_{1}, H_{2}, H_{3}$ be real Hilbert spaces, let $A: H_{1} \rightarrow H_{3}$ and $B: H_{2} \rightarrow H_{3}$ be two bounded linear operators, and let $U: H_{1} \rightarrow H_{1}$ and $T: \mathrm{H}_{2} \rightarrow \mathrm{H}_{2}$ be two firmly quasi-nonexpansive mappings. The SEFP in [6] is to

$$
\text { find } x^{*} \in F(U), y^{*} \in F(T) \quad \text { such that } A x^{*}=B y^{*} \text {, }
$$

where $F(U)$ and $F(T)$ denote the sets of the fixed points of mappings $U$ and $T$, respectively. The goal is to cover many situations, for instance, in decomposition methods for PDFs and applications in game theory and in intensity-modulated radiation therapy (IMRT).

For solving the SEFP (3), Moudafi and Al-Shemas [6] introduced the following simultaneous iterative method:

$$
\begin{aligned}
& x_{k+1}=U\left(x_{k}-\gamma_{k} A^{*}\left(A x_{k}-B y_{k}\right)\right), \\
& y_{k+1}=T\left(y_{k}+\gamma_{k} B^{*}\left(A x_{k}-B y_{k}\right)\right),
\end{aligned}
$$

for firmly quasi-nonexpansive mappings $U$ and $T$, where $\gamma_{k} \in$ $\left(\epsilon, 2 /\left(\lambda_{A}+\lambda_{B}\right)-\epsilon\right)$ and $\lambda_{A}$ and $\lambda_{B}$ stand for the spectral radii of $A^{*} A$ and $B^{*} B$, respectively. 
In 2014, Zhao [7] introduced the following simultaneous Mann iterative algorithm:

$$
\begin{aligned}
u_{k} & =x_{k}-\gamma_{k} A^{*}\left(A x_{k}-B y_{k}\right), \\
x_{k+1} & =\left(1-\alpha_{k}\right) u_{k}+\alpha_{k} U\left(u_{k}\right), \\
v_{k} & =y_{k}+\gamma_{k} B^{*}\left(A x_{k}-B y_{k}\right), \\
y_{k+1} & =\left(1-\beta_{k}\right) v_{k}+\beta_{k} T\left(v_{k}\right),
\end{aligned}
$$

where the step size $\left\{\gamma_{k}\right\}$ does not depend on the operator norms $\|A\|$ and $\|B\|$. And she proved the weak convergence of this algorithm (5) to solve SEFP (3) governed by quasinonexpansive operators $U$ and $T$.

Recently, the multiple-set split equality common fixedpoint problem (MSECFP) studied by Zhao and Wang [8] is to

$$
\begin{aligned}
& \text { find } x^{*} \in \bigcap_{i=1}^{p} F\left(U_{i}\right), y^{*} \in \bigcap_{j=1}^{q} F\left(T_{j}\right) \\
& \text { such that } A x^{*}=B y^{*} \text {, }
\end{aligned}
$$

where $p, q \geq 1$ are integers. They introduced the following two mixed iterative algorithms for solving the MSECFP (6) of quasi-nonexpansive mappings:

$$
\begin{aligned}
u_{k} & =x_{k}-\gamma_{k} A^{*}\left(A x_{k}-B y_{k}\right), \\
x_{k+1} & =\alpha_{k}^{0} u_{k}+\alpha_{k}^{1} U_{1}\left(u_{k}\right)+\cdots+\alpha_{k}^{p} U_{p}\left(u_{k}\right), \\
v_{k} & =y_{k}+\gamma_{k} B^{*}\left(A x_{k}-B y_{k}\right), \\
y_{k+1} & =\beta_{k} v_{k}+\left(1-\beta_{k}\right) T_{j(k)}\left(v_{k}\right)
\end{aligned}
$$

and

$$
\begin{aligned}
u_{k} & =x_{k}-\gamma_{k} A^{*}\left(A x_{k}-B y_{k}\right), \\
x_{k+1} & =\alpha_{k} u_{k}+\left(1-\alpha_{k}\right) U_{i(k)}\left(u_{k}\right), \\
v_{k} & =y_{k}+\gamma_{k} B^{*}\left(A x_{k}-B y_{k}\right), \\
y_{k+1} & =\beta_{k}^{0} v_{k}+\beta_{k}^{1} T_{1}\left(v_{k}\right)+\cdots+\beta_{k}^{q} T_{q}\left(v_{k}\right),
\end{aligned}
$$

where the step size $\left\{\gamma_{k}\right\}$ does not depend on the operator norms $\|A\|$ and $\|B\|$. And they proved the weak convergence of such algorithms.

Very recently, Wang and Kim [9] introduced the following iterative scheme for solving SEFP (3) of demicontractive mappings,

$$
\begin{aligned}
\forall x_{0} & \in H_{1}, \quad y_{0} \in H_{2}, \\
u_{k} & =x_{k}-\gamma_{k} A^{*}\left(A x_{k}-B y_{k}\right), \\
w_{k} & =\left(1-t_{k}\right) u_{k}, \\
x_{k+1} & =\alpha_{k} w_{k}+\left(1-\alpha_{k}\right) U\left(w_{k}\right), \\
v_{k} & =y_{k}+\gamma_{k} B^{*}\left(A x_{k}-B y_{k}\right), \\
p_{k} & =\left(1-t_{k}\right) v_{k}, \\
y_{k+1} & =\beta_{k} p_{k}+\left(1-\beta_{k}\right) T\left(p_{k}\right),
\end{aligned}
$$

and obtain a strong convergence result with no compactness assumptions on the spaces or the mappings and with no extra conditions on the fixed-point sets.

Inspired and motivated by the works mentioned above, we consider the mixed parallel and cyclic iterative algorithms for MSECFP (6) of demicontractive mappings which are a generalization of quasi-nonexpansive mappings without prior knowledge of operator norms in Hilbert spaces. Under some mild assumptions, we prove weak and strong convergence results of such algorithms for solving MSECFP (6).

\section{Preliminaries}

Throughout this paper, we always assume that $H_{1}, H_{2}, H_{3}$ are real Hilbert spaces and let $\mathbb{N}$ and $\mathbb{R}$ be the set of positive integers and real numbers, respectively. In what follows, we denote strong and weak convergence in the space by " $\rightarrow$ " and " $\rightarrow$ ", respectively, and the set of the fixed points of a mapping $T$ by $F(T)$. Also, we use $\omega_{w}\left(x_{k}\right)=\left\{x: \exists x_{k_{j}} \rightarrow x\right\}$ to represent weak $\omega$-limit set of $\left\{x_{k}\right\}$.

Let $C$ be a nonempty closed convex subset of a Hilbert space $H$. The metric (or nearest point) projection $P_{C}$ from $H$ onto $C$ is defined as follows: given $x \in H$, the unique point $P_{C} x \in C$ satisfies the property

$$
\left\|x-P_{C} x\right\|=\inf _{y \in C}\|x-y\| .
$$

It is well known [10] that $P_{C}$ is a nonexpansive mapping and is characterized by the inequality

$$
\begin{gathered}
P_{C} x \in C, \\
\left\langle x-P_{C} x, y-P_{C} x\right\rangle \leq 0, \quad \forall y \in C .
\end{gathered}
$$

Definition 1. Let $H$ be a real Hilbert space. A mapping $T$ : $H \rightarrow H$ is said to be

(i) nonexpansive if $\|T x-T y\| \leq\|x-y\|, \forall x, y \in H$;

(ii) quasi-nonexpansive if $F(T) \neq \emptyset$ and if $\|T x-q\| \leq$ $\|x-q\|, \forall x \in H, q \in F(T) ;$

(iii) firmly nonexpansive if

$$
\begin{array}{r}
\|T x-T y\|^{2} \leq\|x-y\|^{2}-\|(I-T) x-(I-T) y\|^{2}, \\
\forall x, y \in H,
\end{array}
$$

or equivalently

$$
\|T x-T y\|^{2} \leq\langle x-y, T x-T y\rangle, \quad \forall x, y \in H ;
$$

(iv) firmly quasi-nonexpansive if $F(T) \neq \emptyset$ and

$$
\begin{aligned}
\|T x-q\|^{2} \leq\|x-q\|^{2}-\|x-T x\|^{2} & \\
& \forall x \in H, q \in F(T) ;
\end{aligned}
$$

(v) $\mu$-demicontractive if $F(T) \neq \emptyset$ and there exists a constant $\mu \in(-\infty, 1)$ such that

$$
\|T x-q\|^{2} \leq\|x-q\|^{2}+\mu\|x-T x\|^{2},
$$

$\forall x \in H, q \in F(T)$. 
Remark 2. Notice that every 0-demicontractive mapping is exactly quasi-nonexpansive. In particular, we say that it is quasi-strictly pseudocontractive [11] if $0 \leq \mu<1$. Moreover, if $\mu \leq 0$, every $\mu$-demicontractive mapping becomes quasinonexpansive. Therefore, it is sufficient to only take $\mu \in(0,1)$ in (v) of Definition 1 in Hilbert spaces. However, as seen in (iv) of Definition 1, every firmly quasi-nonexpansive mapping (often called to be a directed operator [12])) is obviously (-1)demicontractive.

It is worth noting that the class of demicontractive mappings is more general than the class of quasi-nonexpansive mappings and the class of firmly quasi-nonexpansive mappings.

Definition 3. Let $H$ be a real Hilbert space. An operator $T$ : $H \rightarrow H$ is called demiclosed at origin for any sequence $\left\{x_{k}\right\}$ which converges weakly to $x$, and if the sequence $\left\{T x_{n}\right\}$ converges strongly to 0 , then $T x=0$.

As a special case of the demicloseness principle on uniformly convex Banach spaces given by [13], we know that if $C$ is a nonempty closed convex subset of a Hilbert space $H$ and $T: C \rightarrow H$ is a nonexpansive mapping, then the mapping $I-T$ is demiclosed on $C$. Now, the following question naturally arises: If $T: C \rightarrow H$ is quasi-nonexpansive, is $I-T$ still demiclosed on $C$ ? The answer is negative even at 0 as follows.

Example 4 (see [9]; Example 2.11). The mapping $T:[0,1] \rightarrow$ $[0,1]$ is defined by

$$
T x= \begin{cases}\frac{x}{5}, & x \in\left[0, \frac{1}{2}\right], \\ x \sin \pi x, & x \in\left(\frac{1}{2}, 1\right] .\end{cases}
$$

Then, $T$ is a quasi-nonexpansive mapping, but $I-T$ is not demiclosed at 0 .

Definition 5. Let $S$ be a nonempty closed convex subset of a real Hilbert space $H$. A sequence $\left\{x_{n}\right\} \subset H$ is Fejér-monotone relative to the target set $S$ (simply $S$-Fejérian) if

$$
\left\|x_{n+1}-a\right\| \leq\left\|x_{n}-a\right\|, \quad \forall a \in S, n \geq 1 .
$$

Lemma 6 (see [14]). Let $H$ be a real Hilbert space. Then, for all $t \in[0,1]$ and $x, y \in H$,

$$
\begin{aligned}
\|t x+(1-t) y\|^{2}= & t\|x\|^{2}+(1-t)\|y\|^{2} \\
& -t(1-t)\|x-y\|^{2} .
\end{aligned}
$$

Since the square of the norm is convex, we have the following lemma.

Lemma 7. Let $H$ be a real Hilbert space. Then,

$$
\left\|\alpha_{0} x_{0}+\alpha_{1} x_{1}+\cdots+\alpha_{r} x_{r}\right\|^{2} \leq \sum_{i=0}^{r} \alpha_{i}\left\|x_{i}\right\|^{2}
$$

for $x_{i} \in H, \alpha_{i} \in[0,1], i=0,1,2, \ldots, r$, and $\sum_{i=0}^{r} \alpha_{i}=1$.
Lemma 8 (see [15]). Let $T: H \rightarrow H$ be $\mu$-demicontractive with $F(T) \neq \emptyset$ and set $T_{\alpha}=(1-\alpha) I+\alpha T$ for $\alpha \in(0,1]$. Then, $T_{\alpha}$ is quasi-nonexpansive for $\alpha \in[0,1-\mu]$ and

$$
\begin{array}{r}
\left\|T_{\alpha} x-q\right\|^{2} \leq\|x-q\|^{2}-\alpha(1-\mu-\alpha)\|x-T x\|^{2}, \\
\forall x \in H, q \in F(T) .
\end{array}
$$

Lemma 9 (see [11]; Proposition 2.1). Assume that $C$ is a closed convex subset of a Hilbert space $H$. Let $T: C \rightarrow C$ be a mapping. If $T$ is a $\mu$-demicontractive mapping (which is also called $\mu$-quasi-strict pseudocontraction in [11]), then the fixedpoint set $F(T)$ is closed and convex.

Lemma 10 (see [16]). Let $X$ and $Y$ be Banach spaces and $A$ be a continuous linear operator from $X$ to $Y$. Then, $A$ is weakly continuous.

Lemma 11 (see $[17,18])$. Let $S$ be a nonempty closed convex subset of a real Hilbert space $H$. Suppose that $\left\{x_{n}\right\} \subset H$ is $S$ Fejérian. Then, $x_{n} \rightarrow x \in S$ if and only if $\omega_{w}\left(x_{n}\right) \subset S$.

Lemma 12 (see [19]; Lemma 3.1). Let $\left\{\Gamma_{n}\right\}$ be a sequence of real numbers that does not decrease at infinity in the sense that there exists a subsequence $\left\{\Gamma_{n_{i}}\right\}$ of $\left\{\Gamma_{n}\right\}$ which satisfies $\Gamma_{n_{i}}<\Gamma_{n_{i}+1}$ for all $i \in \mathbb{N}$. Define the sequence $\{\tau(n)\}_{n \geq n_{0}}$ of integers as follows:

$$
\tau(n)=\max \left\{k \leq n: \Gamma_{k}<\Gamma_{k+1}\right\},
$$

where $n_{0} \in \mathbb{N}$ such that $\left.\left\{k \leq n_{0}: \Gamma_{k}<\Gamma_{k+1}\right\}\right\} \neq \emptyset$. Then, there hold the following properties:

(i) $\tau\left(n_{0}\right) \leq \tau\left(n_{0}+1\right) \leq \cdots$ and $\tau(n) \rightarrow \infty$;

(ii) $\Gamma_{\tau(n)} \leq \Gamma_{\tau(n)+1}$ and $\Gamma_{n} \leq \Gamma_{\tau(n)+1}, \forall n \geq n_{0}$.

Lemma 13 (see [20]). Assume that $\left\{a_{k}\right\}$ is a sequence of nonnegative real numbers such that

$$
a_{k+1} \leq\left(1-\lambda_{k}\right) a_{k}+\lambda_{k} \delta_{k}, \quad \forall k \geq 0,
$$

where $\left\{\lambda_{k}\right\}$ is a sequence in $(0,1)$ and $\left\{\delta_{k}\right\}$ is a sequence in $\mathbb{R}$ such that

(a) $\sum_{k=0}^{\infty} \lambda_{k}=\infty$ and $\lim _{k \rightarrow \infty} \lambda_{k}=0$;

(b) $\lim \sup _{k \rightarrow \infty} \delta_{k} \leq 0$ or $\sum_{k=0}^{\infty} \lambda_{k}\left|\delta_{k}\right|<\infty$.

Then, $\lim _{k \rightarrow \infty} a_{k}=0$.

\section{Main Results}

In this section, we study two mixed parallel and cyclic iterative algorithms for MSECFP (6) of demicontractive mappings where the step sizes do not depend on the operator norms $\|A\|$ and $\|B\|$, and we prove the weak and strong convergence of such algorithms. Denote the solution set of $\operatorname{MSECFP}(6)$ by $\Omega$; that is,

$$
\begin{aligned}
\Omega & :=\left\{(x, y) \mid x \in \bigcap_{i=1}^{p} F\left(U_{i}\right), y\right. \\
& \left.\in \bigcap_{j=1}^{q} F\left(T_{j}\right) \text { such that } A x=B y\right\} .
\end{aligned}
$$


Given two positive integers $p$ and $q$, the $p$-mod function $i$ takes values in the set $\{1,2, \ldots, p\}$ and the $q$-mod function $j$ takes values in the set $\{1,2, \ldots, q\}$ as

$$
i(k)=r+1, \quad 0 \leq r \leq p-1,
$$

for $k=n p+r$ for some integers $n \geq 0$ and $0 \leq r<p$, and

$$
j(k)=r+1, \quad 0 \leq r \leq q-1,
$$

for $k=n q+r$ for some integers $n \geq 0$ and $0 \leq r<q$. follows:

Put $H^{*}=H_{1} \times H_{2}$. Define the inner product on $H^{*}$ as

$$
\begin{aligned}
\left\langle\left(x_{1}, y_{1}\right),\left(x_{2}, y_{2}\right)\right\rangle=\left\langle x_{1}, x_{2}\right\rangle+\left\langle y_{1}, y_{2}\right\rangle & \\
& \forall\left(x_{1}, y_{1}\right),\left(x_{2}, y_{2}\right) \in H^{*}
\end{aligned}
$$

It is easy to see that $H^{*}$ is a real Hilbert space and

$$
\|(x, y)\|=\left(\|x\|^{2}+\|y\|^{2}\right)^{1 / 2}, \quad \forall(x, y) \in H^{*} .
$$

Note also that if $\left\{\left(x_{k}, y_{k}\right)\right\}$ is a sequence in $H^{*}$, there holds the following relation:

$$
\left(x^{*}, y^{*}\right) \in \omega_{w}\left(x_{k}, y_{k}\right) \Longrightarrow x^{*} \in \omega_{w}\left(x_{k}\right), \quad y^{*} \in \omega_{w}\left(y_{k}\right) .
$$

Algorithm 14. Let $x_{0} \in H_{1}, y_{0} \in H_{2}$ be arbitrary and $p, q \geq 1$ be integers. Let $\left\{\alpha_{k}^{i}\right\} \subset[0,1](0 \leq i \leq p)$ such that $\sum_{i=0}^{p} \alpha_{k}^{i}=$ 1 and $\left\{\beta_{k}\right\} \subset[0,1]$. Assume that the $k$ th iterate $\left(x_{k}, y_{k}\right) \in$ $H^{*}$ has been constructed and $A x_{k}-B y_{k} \neq 0$, and then we calculate the $(k+1)$ th iterate $\left(x_{k+1}, y_{k+1}\right)$ via the formulas

$$
\begin{aligned}
u_{k} & =x_{k}-\gamma_{k} A^{*}\left(A x_{k}-B y_{k}\right), \\
x_{k+1} & =\alpha_{k}^{0} u_{k}+\alpha_{k}^{1} U_{1}\left(u_{k}\right)+\cdots+\alpha_{k}^{p} U_{p}\left(u_{k}\right), \\
v_{k} & =y_{k}+\gamma_{k} B^{*}\left(A x_{k}-B y_{k}\right), \\
y_{k+1} & =\left(1-\beta_{k}\right) v_{k}+\beta_{k} T_{j(k)}\left(v_{k}\right) .
\end{aligned}
$$

Assume the step size $\gamma_{k}$ is chosen in such a way that

$\gamma_{k}$

$$
\epsilon\left(\varepsilon, \min \left\{\eta, \frac{2\left\|A x_{k}-B y_{k}\right\|^{2}}{\left\|A^{*}\left(A x_{k}-B y_{k}\right)\right\|^{2}+\left\|B^{*}\left(A x_{k}-B y_{k}\right)\right\|^{2}}\right\}-\varepsilon\right)
$$

for all $k \in \widetilde{\Omega}$ and some small enough $\varepsilon>0$, where the index set $\widetilde{\Omega}=\left\{k: A x_{k}-B y_{k} \neq 0\right\}$,

$$
\begin{aligned}
& \eta=\frac{2\left\|A x_{l}-B y_{l}\right\|^{2}}{\left\|A^{*}\left(A x_{l}-B y_{l}\right)\right\|^{2}+\left\|B^{*}\left(A x_{l}-B y_{l}\right)\right\|^{2}}, \\
& l=\min _{k \in \widetilde{\Omega}}\{k\} ;
\end{aligned}
$$

otherwise, $\gamma_{k}=\gamma\left(\gamma\right.$ being any nonnegative value). If $A x_{k}=$ $B y_{k}=0$, then we take $u_{k}=x_{k}, v_{k}=y_{k}$ and

$$
\begin{aligned}
& x_{k+1}=\alpha_{k}^{0} x_{k}+\alpha_{k}^{1} U_{1}\left(x_{k}\right)+\cdots+\alpha_{k}^{p} U_{p}\left(x_{k}\right), \\
& y_{k+1}=\left(1-\beta_{k}\right) y_{k}+\beta_{k} T_{j(k)} y_{k} .
\end{aligned}
$$

Algorithm 15. Let $x_{0} \in H_{1}, y_{0} \in H_{2}$ be arbitrary and $p, q \geq 1$ be integers. Let $\left\{\alpha_{k}^{i}\right\} \subset[0,1](0 \leq i \leq p)$ such that $\sum_{i=0}^{p} \alpha_{k}^{i}=1$ and $\left\{\beta_{k}\right\} \subset[0,1],\left\{t_{k}\right\} \subset(0,1)$. Assume that the $k$ th iterate $\left(x_{k}, y_{k}\right) \in H^{*}$ has been constructed and $A x_{k}-B y_{k} \neq 0$, and then we calculate the $(k+1)$ th iterate $\left(x_{k+1}, y_{k+1}\right)$ via the formulas

$$
\begin{aligned}
u_{k} & =x_{k}-\gamma_{k} A^{*}\left(A x_{k}-B y_{k}\right), \\
w_{k} & =\left(1-t_{k}\right) u_{k}, \\
x_{k+1} & =\alpha_{k}^{0} w_{k}+\alpha_{k}^{1} U_{1}\left(w_{k}\right)+\cdots+\alpha_{k}^{p} U_{p}\left(w_{k}\right), \\
v_{k} & =y_{k}+\gamma_{k} B^{*}\left(A x_{k}-B y_{k}\right), \\
p_{k} & =\left(1-t_{k}\right) v_{k}, \\
y_{k+1} & =\left(1-\beta_{k}\right) p_{k}+\beta_{k} T_{j(k)}\left(p_{k}\right) .
\end{aligned}
$$

Assume that $\widetilde{\Omega}, \eta, l$ are the same as in Algorithm 14 and for $k \in \widetilde{\Omega}$ the step size $\gamma_{k}$ is chosen as (30); otherwise, $\gamma_{k}=\gamma(\gamma$ being any nonnegative value). If $A x_{k}=B y_{k}=0$, then we take $u_{k}=x_{k}, v_{k}=y_{k}$ and

$$
\begin{aligned}
w_{k} & =\left(1-t_{k}\right) x_{k}, \\
x_{k+1} & =\alpha_{k}^{0} w_{k}+\alpha_{k}^{1} U_{1}\left(w_{k}\right)+\cdots+\alpha_{k}^{p} U_{p}\left(w_{k}\right), \\
p_{k} & =\left(1-t_{k}\right) y_{k}, \\
y_{k+1} & =\left(1-\beta_{k}\right) p_{k}+\beta_{k} T_{j(k)}\left(p_{k}\right) .
\end{aligned}
$$

Now, we will see from Lemma 16 that $\left\{\gamma_{k}\right\}$ is well defined and bounded. The proof of the following lemma is also added for completing the proof of Lemma 2.3 in [7] for the sake of convenience.

Lemma 16. Assume the solution set $\Omega$ of (6) is nonempty. Then, $\left\{\gamma_{k}\right\}$ defined by (30) is well defined and bounded.

Proof. Take $(x, y) \in \Omega$, that is, $x \in \bigcap_{i=1}^{p} F\left(U_{i}\right), y \in$ $\bigcap_{j=1}^{q} F\left(T_{j}\right)$, and $A x=B y$. We have

$$
\begin{aligned}
& \left\langle A^{*}\left(A x_{k}-B y_{k}\right), x_{k}-x\right\rangle \\
& \quad=\left\langle A x_{k}-B y_{k}, A x_{k}-A x\right\rangle \\
& \left\langle B^{*}\left(A x_{k}-B y_{k}\right), y-y_{k}\right\rangle=\left\langle A x_{k}-B y_{k}, B y-B y_{k}\right\rangle .
\end{aligned}
$$

By adding the above two equalities and by taking $A x=B y$ into account, we obtain

$$
\begin{aligned}
\left\|A x_{k}-B y_{k}\right\|^{2}= & \left\langle A^{*}\left(A x_{k}-B y_{k}\right), x_{k}-x\right\rangle \\
& +\left\langle B^{*}\left(A x_{k}-B y_{k}\right), y-y_{k}\right\rangle \\
\leq & \left\|A^{*}\left(A x_{k}-B y_{k}\right)\right\|\left\|x_{k}-x\right\| \\
& +\left\|B^{*}\left(A x_{k}-B y_{k}\right)\right\|\left\|y-y_{k}\right\| .
\end{aligned}
$$


Consequently, for $k \in \Omega$, that is, $\left\|A x_{k}-B y_{k}\right\|>0$, we have $\left\|A^{*}\left(A x_{k}-B y_{k}\right)\right\| \neq 0$ or $\left\|B^{*}\left(A x_{k}-B y_{k}\right)\right\| \neq 0$. And since

$$
\begin{aligned}
& \left\|A^{*}\left(A x_{k}-B y_{k}\right)\right\|^{2} \leq\left\|A^{*}\right\|^{2}\left\|A x_{k}-B y_{k}\right\|^{2}, \\
& \left\|B^{*}\left(A x_{k}-B y_{k}\right)\right\|^{2} \leq\left\|B^{*}\right\|^{2}\left\|A x_{k}-B y_{k}\right\|^{2},
\end{aligned}
$$

we have

$$
\begin{gathered}
\frac{2\left\|A x_{k}-B y_{k}\right\|^{2}}{\left\|A^{*}\left(A x_{k}-B y_{k}\right)\right\|^{2}+\left\|B^{*}\left(A x_{k}-B y_{k}\right)\right\|^{2}} \\
\geq \frac{2}{\left\|A^{*}\right\|^{2}+\left\|B^{*}\right\|^{2}}=\frac{2}{\|A\|^{2}+\|B\|^{2}} .
\end{gathered}
$$

Thus, we can choose small enough $\varepsilon \in\left(0,1 /\left(\|A\|^{2}+\|B\|^{2}\right)\right)$. This causes $\left\{\gamma_{k}\right\}$ to be well defined. From (30), we obtain that $\gamma_{k} \in(\varepsilon, \eta-\varepsilon)$ and $\eta$ is a fixed positive number, so $\left\{\gamma_{k}\right\}$ is bounded.

Assumption 17. Assume that

(i) the solution set $\Omega$ of (6) is nonempty;

(ii) $U_{i}: H_{1} \rightarrow H_{1}(1 \leq i \leq p)$ and $T_{j}: H_{2} \rightarrow$ $H_{2}(1 \leq j \leq q)$ are $\tau_{i}$-demicontractive and $\mu_{j^{-}}$ demicontractive, respectively;

(iii) $I-U_{i}(1 \leq i \leq p)$ and $I-T_{j}(1 \leq j \leq q)$ are demiclosed at origin.

Let $\tau=\max _{1 \leq i \leq p} \tau_{i}$ and $\mu=\max _{1 \leq j \leq q} \mu_{j}$. Clearly, $U_{i}$ is $\tau$ demicontractive for all $1 \leq i \leq p$ and $T_{j}$ is $\mu$-demicontractive for all $1 \leq j \leq q$

Lemma 18. Given two bounded linear operators $A: H_{1} \rightarrow H_{3}$ and $B: H_{2} \rightarrow H_{3}$, let $U_{i}: H_{1} \rightarrow H_{1}(1 \leq i \leq p)$ and $T_{j}: H_{2} \rightarrow H_{2}(1 \leq j \leq q)$ be $\tau_{i}$-demicontractive and $\mu_{j^{-}}$ demicontractive, respectively. Assume that the solution set $\Omega$ of (6) is nonempty. Then, $\Omega$ is a nonempty closed convex set.

Proof. By Lemma 9, we have that $F\left(T_{i}\right)(1 \leq i \leq p)$ and $F\left(U_{j}\right)(1 \leq j \leq q)$ are both closed convex subsets, and since $A$ and $B$ are both linear, it is easy to see that $\Omega$ is a closed convex subset in $H^{*}$.

Lemma 19 (see [21]; Lemma 3.1). Let $\left\{u_{k}\right\}$ be a bounded sequence of a Hilbert space $H$. Let $q$ be a positive integer and $J=\{1,2, \ldots, q\}$. If $\lim _{k \rightarrow \infty}\left\|u_{k+1}-u_{k}\right\|=0$ and $x^{*} \in \omega_{w}\left(u_{k}\right)$, then, for any $j \in J$, there exists a subsequence $\left\{u_{k_{m}}\right\}$ of $\left\{u_{k}\right\}$ depending on $j$ such that $j\left(k_{m}\right)=j$ and $u_{k_{m}} \rightarrow x^{*}$.

Theorem 20. Let Assumption 17 be satisfied. Given two bounded linear operators $A: H_{1} \rightarrow H_{3}$ and $B: H_{2} \rightarrow H_{3}$, if the following conditions are satisfied:

(a) $\tau<\liminf _{k \rightarrow \infty} \alpha_{k}^{0}$ and $\liminf _{k \rightarrow \infty} \alpha_{k}^{i}>0(1 \leq i \leq$ $p)$,

(b) $0<\liminf _{k \rightarrow \infty} \beta_{k} \leq \lim \sup _{k \rightarrow \infty} \beta_{k}<1-\mu$,

then the sequence $\left\{\left(x_{k}, y_{k}\right)\right\}$ generated by Algorithm 14 converges weakly to a solution of (6).
Proof. First, we claim that the sequence $\left\{\left(x_{k}, y_{k}\right)\right\}$ is $\Omega$ Fejérian. Indeed, taking $\left(x^{*}, y^{*}\right) \in \Gamma$, that is, $x^{*} \in \bigcap_{i=1}^{p} F\left(U_{i}\right)$, $y^{*} \in \bigcap_{j=1}^{q} F\left(T_{j}\right)$, and $A x^{*}=B y^{*}$, by Algorithm 14, we obtain

$$
\begin{aligned}
\left\|u_{k}-x^{*}\right\|^{2}= & \left\|x_{k}-\gamma_{k} A^{*}\left(A x_{k}-B y_{k}\right)-x^{*}\right\|^{2} \\
= & \left\|x_{k}-x^{*}\right\|^{2} \\
& -2 \gamma_{k}\left\langle x_{k}-x^{*}, A^{*}\left(A x_{k}-B y_{k}\right)\right\rangle \\
& +\gamma_{k}^{2}\left\|A^{*}\left(A x_{k}-B y_{k}\right)\right\|^{2} \\
= & \left\|x_{k}-x^{*}\right\|^{2} \\
& -2 \gamma_{k}\left\langle A x_{k}-A x^{*}, A x_{k}-B y_{k}\right\rangle \\
& +\gamma_{k}^{2}\left\|A^{*}\left(A x_{k}-B y_{k}\right)\right\|^{2} .
\end{aligned}
$$

Similarly, we have

$$
\begin{aligned}
\left\|v_{k}-y^{*}\right\|^{2}= & \left\|y_{k}+\gamma_{k} B^{*}\left(A x_{k}-B y_{k}\right)-y^{*}\right\|^{2} \\
= & \left\|y_{k}-y^{*}\right\|^{2} \\
& +2 \gamma_{k}\left\langle y_{k}-y^{*}, B^{*}\left(A x_{k}-B y_{k}\right)\right\rangle \\
& +\gamma_{k}^{2}\left\|B^{*}\left(A x_{k}-B y_{k}\right)\right\|^{2} \\
= & \left\|y_{k}-y^{*}\right\|^{2} \\
& +2 \gamma_{k}\left\langle B y_{k}-B y^{*}, A x_{k}-B y_{k}\right\rangle \\
& +\gamma_{k}^{2}\left\|B^{*}\left(A x_{k}-B y_{k}\right)\right\|^{2} .
\end{aligned}
$$

It follows from the above inequalities and $A x^{*}=B y^{*}$ that

$$
\begin{aligned}
& \left\|u_{k}-x^{*}\right\|^{2}+\left\|v_{k}-y^{*}\right\|^{2}=\left\|x_{k}-x^{*}\right\|^{2}+\left\|y_{k}-y^{*}\right\|^{2} \\
& -2 \gamma_{k}\left\langle A x_{k}-A x^{*}-B y_{k}+B y^{*}, A x_{k}-B y_{k}\right\rangle \\
& +\gamma_{k}^{2}\left\|A^{*}\left(A x_{k}-B y_{k}\right)\right\|^{2}+\gamma_{k}^{2}\left\|B^{*}\left(A x_{k}-B y_{k}\right)\right\|^{2} \\
& =\left\|x_{k}-x^{*}\right\|^{2}+\left\|y_{k}-y^{*}\right\|^{2}-\gamma_{k}\left[2\left\|A x_{k}-B y_{k}\right\|^{2}\right. \\
& \left.-\gamma_{k}\left(\left\|A^{*}\left(A x_{k}-B y_{k}\right)\right\|^{2}+\left\|B^{*}\left(A x_{k}-B y_{k}\right)\right\|^{2}\right)\right] .
\end{aligned}
$$

Taking $\omega_{k}^{i}=\alpha_{k}^{i} /\left(1-\alpha_{k}^{0}\right)(1 \leq i \leq p)$, we have $\sum_{i=1}^{p} \omega_{k}^{i}=1$ for every $k \geq 0$ and $\left(1-\alpha_{k}^{0}\right) \sum_{i=1}^{p} \omega_{k}^{i}=\sum_{i=1}^{p} \alpha_{k}^{i}$. It follows from (29) that

$$
\begin{aligned}
x_{k+1} & =\alpha_{k}^{0} u_{k}+\left(1-\alpha_{k}^{0}\right) \sum_{i=1}^{p} \omega_{k}^{i} U_{i}\left(u_{k}\right) \\
& =\sum_{i=1}^{p} \omega_{k}^{i}\left(\alpha_{k}^{0} u_{k}+\left(1-\alpha_{k}^{0}\right) U_{i}\left(u_{k}\right)\right) .
\end{aligned}
$$

Using Lemma 8 for any $i \in\{1,2, \ldots, p\}$, we have

$$
\begin{aligned}
& \left\|\alpha_{k}^{0} u_{k}+\left(1-\alpha_{k}^{0}\right) U_{i}\left(u_{k}\right)-x^{*}\right\|^{2} \\
& \quad \leq\left\|u_{k}-x^{*}\right\|^{2}-\left(1-\alpha_{k}^{0}\right)\left(\alpha_{k}^{0}-\tau\right)\left\|U_{i}\left(u_{k}\right)-u_{k}\right\|^{2} .
\end{aligned}
$$


Thus, by (43) and (44) and Lemma 7, we obtain

$$
\begin{aligned}
& \left\|x_{k+1}-x^{*}\right\|^{2} \leq \sum_{i=1}^{p} \omega_{k}^{i}\left\|\alpha_{k}^{0} u_{k}+\left(1-\alpha_{k}^{0}\right) U_{i}\left(u_{k}\right)-x^{*}\right\|^{2} \\
& \leq \sum_{i=1}^{p} \omega_{k}^{i} \\
& \cdot\left(\left\|u_{k}-x^{*}\right\|^{2}-\left(1-\alpha_{k}^{0}\right)\left(\alpha_{k}^{0}-\tau\right)\left\|U_{i}\left(u_{k}\right)-u_{k}\right\|^{2}\right) \\
& =\left\|u_{k}-x^{*}\right\|^{2}-\left(1-\alpha_{k}^{0}\right)\left(\alpha_{k}^{0}-\tau\right) \sum_{i=1}^{p} \omega_{k}^{i} \\
& \cdot\left\|U_{i}\left(u_{k}\right)-u_{k}\right\|^{2} .
\end{aligned}
$$

By (ii) of Assumption 17 and from (29) and Lemma 6, we also have

$$
\begin{aligned}
\left\|y_{k+1}-y^{*}\right\|^{2} & \\
= & \left\|\left(1-\beta_{k}\right)\left(v_{k}-y^{*}\right)+\beta_{k}\left(T_{j(k)} v_{k}-y^{*}\right)\right\|^{2} \\
= & \left(1-\beta_{k}\right)\left\|v_{k}-y^{*}\right\|^{2}+\beta_{k}\left\|T_{j(k)} v_{k}-y^{*}\right\|^{2} \\
& -\beta_{k}\left(1-\beta_{k}\right)\left\|T_{j(k)} v_{k}-v_{k}\right\|^{2} \\
\leq & \left(1-\beta_{k}\right)\left\|v_{k}-y^{*}\right\|^{2}+\beta_{k}\left\|v_{k}-y^{*}\right\|^{2} \\
& +\mu \beta_{k}\left\|T_{j(k)} v_{k}-v_{k}\right\|^{2} \\
& -\beta_{k}\left(1-\beta_{k}\right)\left\|T_{j(k)} v_{k}-v_{k}\right\|^{2} \\
= & \left\|v_{k}-y^{*}\right\|^{2}-\beta_{k}\left(1-\beta_{k}-\mu\right)\left\|v_{k}-T_{j(k)} v_{k}\right\|^{2} .
\end{aligned}
$$

Then, it follows from (42), (45), and (46) that

$$
\begin{aligned}
& \left\|\left(x_{k+1}, y_{k+1}\right)-\left(x^{*}, y^{*}\right)\right\|^{2}=\left\|x_{k+1}-x^{*}\right\|^{2}+\| y_{k+1} \\
& -y^{*}\left\|^{2} \leq\right\| u_{k}-x^{*}\left\|^{2}+\right\| v_{k}-y^{*} \|^{2}-\left(1-\alpha_{k}^{0}\right)\left(\alpha_{k}^{0}\right. \\
& -\tau) \times \sum_{i=1}^{p} \omega_{k}^{i}\left\|U_{i}\left(u_{k}\right)-u_{k}\right\|^{2}-\beta_{k}\left(1-\beta_{k}-\mu\right) \| v_{k} \\
& -T_{j(k)} v_{k}\left\|^{2} \leq\right\| x_{k}-x^{*}\left\|^{2}+\right\| y_{k}-y^{*} \|^{2} \\
& -\gamma_{k}\left[2\left\|A x_{k}-B y_{k}\right\|^{2}\right. \\
& \left.-\gamma_{k}\left(\left\|A^{*}\left(A x_{k}-B y_{k}\right)\right\|^{2}+\left\|B^{*}\left(A x_{k}-B y_{k}\right)\right\|^{2}\right)\right] \\
& -\left(\alpha_{k}^{0}-\tau\right) \times \sum_{i=1}^{p} \alpha_{k}^{i}\left\|U_{i}\left(u_{k}\right)-u_{k}\right\|^{2}-\beta_{k}\left(1-\beta_{k}\right. \\
& -\mu)\left\|v_{k}-T_{j(k)} v_{k}\right\|^{2}
\end{aligned}
$$

$$
\begin{aligned}
\leq & \left\|x_{k}-x^{*}\right\|^{2}+\left\|y_{k}-y^{*}\right\|^{2}-\gamma_{k}\left[2\left\|A x_{k}-B y_{k}\right\|^{2}\right. \\
& \left.-\gamma_{k}\left(\left\|A^{*}\left(A x_{k}-B y_{k}\right)\right\|^{2}+\left\|B^{*}\left(A x_{k}-B y_{k}\right)\right\|^{2}\right)\right] \\
\leq & \left\|\left(x_{k}, y_{k}\right)-\left(x^{*}, y^{*}\right)\right\|^{2}-\gamma_{k} \varepsilon\left(\left\|A^{*}\left(A x_{k}-B y_{k}\right)\right\|^{2}\right. \\
& \left.+\left\|B^{*}\left(A x_{k}-B y_{k}\right)\right\|^{2}\right) \\
\leq & \left\|\left(x_{k}, y_{k}\right)-\left(x^{*}, y^{*}\right)\right\|^{2} .
\end{aligned}
$$

Hence, $\left\{\left(x_{k}, y_{k}\right)\right\}$ is $\Omega$-Fejérian.

Next, we show that, for all $i \in\{1,2, \ldots, p\}, \lim _{k \rightarrow \infty} \| u_{k}-$ $U_{i} u_{k}\left\|=0, \lim _{k \rightarrow \infty}\right\| v_{k}-T_{j(k)} v_{k}\left\|=0, \lim _{k \rightarrow \infty}\right\| u_{k}-x_{k} \|=0$, and $\lim _{k \rightarrow \infty}\left\|v_{k+1}-v_{k}\right\|=0$. In fact, from (50), we see that the sequence $\left\{\left\|\left(x_{k}, y_{k}\right)-\left(x^{*}, y^{*}\right)\right\|^{2}\right\}$ is decreasing and bounded below by 0 . Consequently, it converges to some finite limit. So, the sequences $\left\{x_{k}\right\},\left\{y_{k}\right\},\left\{u_{k}\right\}$, and $\left\{v_{k}\right\}$ are also bounded. Then, from (49) and the assumption on $\left\{\gamma_{k}\right\}$ in (30), it follows that

$$
\lim _{k \rightarrow \infty}\left(\left\|A^{*}\left(A x_{k}-B y_{k}\right)\right\|^{2}+\left\|B^{*}\left(A x_{k}-B y_{k}\right)\right\|^{2}\right)=0,
$$

which together with (48) implies that

$$
\lim _{k \rightarrow \infty}\left\|A x_{k}-B y_{k}\right\|=0 .
$$

Also, from (47) and condition (a), it follows that

$$
\lim _{k \rightarrow \infty} \sum_{i=1}^{p} \alpha_{k}^{i}\left\|U_{i}\left(u_{k}\right)-u_{k}\right\|^{2}=0 .
$$

This, combined with condition (a), implies that, for any $i \in$ $\{1,2, \ldots, p\}$,

$$
\lim _{k \rightarrow \infty}\left\|u_{k}-U_{i}\left(u_{k}\right)\right\|=0 .
$$

It follows from (47) and condition (b) that

$$
\lim _{k \rightarrow \infty}\left\|v_{k}-T_{j(k)} v_{k}\right\|=0 .
$$

Since

$$
\begin{aligned}
\left\|u_{k}-x_{k}\right\| & =\gamma_{k}\left\|A^{*}\left(A x_{k}-B y_{k}\right)\right\| \\
& \leq \gamma_{k}\left\|A^{*}\right\|\left\|A x_{k}-B y_{k}\right\|,
\end{aligned}
$$

it follows from Lemma 16 that $\left\{\gamma_{k}\right\}$ is bounded, so by (52) we have

$$
\lim _{k \rightarrow \infty}\left\|u_{k}-x_{k}\right\|=0
$$

Similarly, we have

$$
\lim _{k \rightarrow \infty}\left\|v_{k}-y_{k}\right\|=0
$$

It follows from (55) and (58) that

$$
\begin{aligned}
\left\|y_{k+1}-y_{k}\right\| \leq & \left(1-\beta_{k}\right)\left\|v_{k}-y_{k}\right\|+\beta_{k}\left\|v_{k}-T_{j(k)} v_{k}\right\| \\
& +\beta_{k}\left\|v_{k}-y_{k}\right\| \\
= & \left\|v_{k}-y_{k}\right\|+\beta_{k}\left\|v_{k}-T_{j(k)} v_{k}\right\| \longrightarrow 0 .
\end{aligned}
$$


Finally, we claim that $\omega_{w}\left(x_{k}, y_{k}\right) \subset \Omega$. To this end, let $(\tilde{x}, \tilde{y}) \in \omega_{w}\left(x_{k}, y_{k}\right)$. From (28), it follows that $\tilde{x} \in \omega_{w}\left(x_{k}\right)$, $\tilde{y} \in \omega_{w}\left(y_{k}\right)$. Since $\omega_{w}\left(x_{k}\right)=\omega_{w}\left(u_{k}\right)$ by (57), we use (54) and Assumption 17(iii) to derive that $\tilde{x} \in \bigcap_{i=1}^{p} F\left(U_{i}\right)$. Given fixed $j \in\{1,2, \ldots, q\}$, since $\left\|y_{k+1}-y_{k}\right\| \rightarrow 0$ and $\tilde{y} \in \omega_{w}\left(y_{k}\right)$, now we apply Lemma 19 to get a subsequence $\left\{y_{k_{m}}\right\}$ of $\left\{y_{k}\right\}$, depending on $j$, such that $y_{k_{m}} \rightarrow \tilde{y}$ and $j\left(k_{m}\right)=j$ for all $m$. Moreover, it turns out that $v_{k_{m}} \rightarrow \tilde{y}$ by (58) and

$$
\lim _{m \rightarrow \infty}\left\|v_{k_{m}}-T_{j} v_{k_{m}}\right\|=\lim _{m \rightarrow \infty}\left\|v_{k_{m}}-T_{j\left(k_{m}\right)} v_{k_{m}}\right\|=0
$$

by virtue of (55). Using Assumption 17(iii) yields $T_{j} \tilde{y}=\tilde{y}$ for any $j \in\{1,2, \ldots, q\}$; that is, $\tilde{y} \in \bigcap_{j=1}^{q} F\left(T_{j}\right)$. On the other hand, by Lemma 10 , we have $A \tilde{x}-B \tilde{y} \in \omega_{w}\left(A x_{k}-B y_{k}\right)$, which together with weakly lower semicontinuity of the norm implies that

$$
\|A \tilde{x}-B \tilde{y}\| \leq \liminf _{k \rightarrow \infty}\left\|A x_{k}-B y_{k}\right\|=0 ;
$$

that is, $A \tilde{x}=B \tilde{y}$; hence, $(\tilde{x}, \tilde{y}) \in \Omega$. Since $\Omega$ is obviously a closed convex set by Lemma 18 and we have shown that $\left\{\left(x_{k}, y_{k}\right)\right\}$ in $H^{*}$ is $\Omega$-Fejérian and $\omega_{w}\left(x_{k}, y_{k}\right) \subset \Omega$, by Lemma 11, we conclude that the sequence $\left\{\left(x_{k}, y_{k}\right)\right\}$ generated by Algorithm 14 converges weakly to a point of $\Omega$.

Let $P_{\Omega}$ be a metric projection from $H^{*}$ onto $\Omega$. We denote the origins of $H_{1}$ and $H_{2}$ by $\theta_{1}$ and $\theta_{2}$, respectively.

Theorem 21. Let Assumption 17 be satisfied. Given two bounded linear operators $A: H_{1} \rightarrow H_{3}$ and $B: H_{2} \rightarrow H_{3}$, if the following conditions are satisfied:

(1) $\tau<\liminf _{k \rightarrow \infty} \alpha_{k}^{0}$ and $\liminf _{k \rightarrow \infty} \alpha_{k}^{i}>0(1 \leq i \leq$ $p)$

(2) $0<\liminf _{k \rightarrow \infty} \beta_{k} \leq \lim \sup _{k \rightarrow \infty} \beta_{k}<1-\mu$;

(3) $\lim _{k \rightarrow \infty} t_{k}=0$ and $\sum_{k=1}^{\infty} t_{k}=\infty$,

then the sequence $\left\{\left(x_{k}, y_{k}\right)\right\}$ generated by Algorithm 15 converges strongly to a solution $P_{\Omega}\left(\theta_{1}, \theta_{2}\right)$ of (6).

Proof. Set $\left(x^{*}, y^{*}\right)=P_{\Omega}\left(\theta_{1}, \theta_{2}\right)$. By (11), we readily see

$$
\left\langle-\left(x^{*}, y^{*}\right),(x, y)-\left(x^{*}, y^{*}\right)\right\rangle \leq 0, \quad \forall(x, y) \in \Omega .
$$

Since $\left(x^{*}, y^{*}\right) \in \Omega$, we have $x^{*} \in \bigcap_{i=1}^{p} F\left(U_{i}\right)$ and $y^{*} \in$ $\bigcap_{j=1}^{q} F\left(T_{j}\right)$ such that $A x^{*}=B y^{*}$. Taking $\delta_{k}^{i}=\alpha_{k}^{i} /(1-$ $\left.\alpha_{k}^{0}\right)(1 \leq i \leq p)$, we have $\sum_{i=1}^{p} \delta_{k}^{i}=1$ for every $k \geq 0$ and $\left(1-\alpha_{k}^{0}\right) \sum_{i=1}^{p} \delta_{k}^{i}=\sum_{i=1}^{p} \alpha_{k}^{i}$. Similar to the proof of (45) and (46), we obtain

$$
\begin{aligned}
& \left\|x_{k+1}-x^{*}\right\|^{2} \\
& \leq\left\|w_{k}-x^{*}\right\|^{2} \\
& \quad-\left(1-\alpha_{k}^{0}\right)\left(\alpha_{k}^{0}-\tau\right) \sum_{i=1}^{p} \delta_{k}^{i}\left\|U_{i}\left(w_{k}\right)-w_{k}\right\|^{2}, \\
& \left\|y_{k+1}-y^{*}\right\|^{2} \\
& \quad \leq\left\|p_{k}-y^{*}\right\|^{2}-\beta_{k}\left(1-\beta_{k}-\mu\right)\left\|p_{k}-T_{j(k)} p_{k}\right\|^{2} .
\end{aligned}
$$

It follows from (33) and (42) that

$$
\begin{aligned}
& \left\|w_{k}-x^{*}\right\|^{2}+\left\|p_{k}-y^{*}\right\|^{2} \leq\left(1-t_{k}\right)\left\|u_{k}-x^{*}\right\|^{2} \\
& +t_{k}\left\|x^{*}\right\|^{2}+\left(1-t_{k}\right)\left\|v_{k}-y^{*}\right\|^{2}+t_{k}\left\|y^{*}\right\|^{2} \leq(1 \\
& \left.-t_{k}\right)\left(\left\|u_{k}-x^{*}\right\|^{2}+\left\|v_{k}-y^{*}\right\|^{2}\right)+t_{k}\left(\left\|x^{*}\right\|^{2}\right. \\
& \left.+\left\|y^{*}\right\|^{2}\right) \leq\left(1-t_{k}\right)\left(\left\|x_{k}-x^{*}\right\|^{2}+\left\|y_{k}-y^{*}\right\|^{2}\right. \\
& -\gamma_{k}\left[2\left\|A x_{k}-B y_{k}\right\|^{2}\right. \\
& \left.\left.-\gamma_{k}\left(\left\|A^{*}\left(A x_{k}-B y_{k}\right)\right\|^{2}+\left\|B^{*}\left(A x_{k}-B y_{k}\right)\right\|^{2}\right)\right]\right) \\
& \quad+t_{k}\left(\left\|x^{*}\right\|^{2}+\left\|y^{*}\right\|^{2}\right) \\
& \leq\left(1-t_{k}\right)\left(\left\|x_{k}-x^{*}\right\|^{2}+\left\|y_{k}-y^{*}\right\|^{2}\right)+t_{k}\left(\left\|x^{*}\right\|^{2}\right. \\
& \left.\quad+\left\|y^{*}\right\|^{2}\right) .
\end{aligned}
$$

By (63), (64), and (66), we have

$$
\begin{aligned}
&\left\|x_{k+1}-x^{*}\right\|^{2}+\left\|y_{k+1}-y^{*}\right\|^{2} \\
& \leq\left\|w_{k}-x^{*}\right\|^{2}+\left\|p_{k}-y^{*}\right\|^{2} \\
& \leq\left(1-t_{k}\right)\left(\left\|x_{k}-x^{*}\right\|^{2}+\left\|y_{k}-y^{*}\right\|^{2}\right) \\
&+t_{k}\left(\left\|x^{*}\right\|^{2}+\left\|y^{*}\right\|^{2}\right) .
\end{aligned}
$$

Now, by setting $\Gamma_{k}=\left\|x_{k}-x^{*}\right\|^{2}+\left\|y_{k}-y^{*}\right\|^{2}$, from the above inequality, we obtain

$$
\Gamma_{k+1} \leq\left(1-t_{k}\right) \Gamma_{k}+t_{k}\left(\left\|x^{*}\right\|^{2}+\left\|y^{*}\right\|^{2}\right) .
$$

By induction, we have

$$
\Gamma_{k+1} \leq \max \left\{\Gamma_{1},\left\|x^{*}\right\|^{2}+\left\|y^{*}\right\|^{2}\right\},
$$

which implies that $\left\{\Gamma_{k}\right\}$ is bounded. Hence, $\left\{x_{k}\right\},\left\{y_{k}\right\},\left\{u_{k}\right\}$, $\left\{v_{k}\right\},\left\{w_{k}\right\}$, and $\left\{p_{k}\right\}$ are all bounded. By (63)-(65), we have

$$
\begin{aligned}
& \Gamma_{k+1} \leq\left\|w_{k}-x^{*}\right\|^{2}+\left\|p_{k}-y^{*}\right\|^{2}-\left(1-\alpha_{k}^{0}\right)\left(\alpha_{k}^{0}-\tau\right) \\
& \quad \times \sum_{i=1}^{p} \delta_{k}^{i}\left\|U_{i}\left(w_{k}\right)-w_{k}\right\|^{2}-\beta_{k}\left(1-\beta_{k}-\mu\right) \| p_{k} \\
& \quad-T_{j(k)} p_{k} \|^{2} \leq\left(1-t_{k}\right) \Gamma_{k}-\left(1-t_{k}\right) \\
& \quad \gamma_{k}\left[2\left\|A x_{k}-B y_{k}\right\|^{2}\right. \\
& \left.\quad-\gamma_{k}\left(\left\|A^{*}\left(A x_{k}-B y_{k}\right)\right\|^{2}+\left\|B^{*}\left(A x_{k}-B y_{k}\right)\right\|^{2}\right)\right] \\
& \quad+t_{k}\left(\left\|x^{*}\right\|^{2}+\left\|y^{*}\right\|^{2}\right)-\left(\alpha_{k}^{0}-\tau\right) \sum_{i=1}^{p} \alpha_{k}^{i} \| U_{i}\left(w_{k}\right) \\
& \quad-w_{k}\left\|^{2}-\beta_{k}\left(1-\beta_{k}-\mu\right)\right\| p_{k}-T_{j(k)} p_{k} \|^{2} .
\end{aligned}
$$


Then, it follows from (70) that

$$
\begin{aligned}
& \left(1-t_{k}\right) \gamma_{k}\left[2\left\|A x_{k}-B y_{k}\right\|^{2}\right. \\
& \left.\quad-\gamma_{k}\left(\left\|A^{*}\left(A x_{k}-B y_{k}\right)\right\|^{2}+\left\|B^{*}\left(A x_{k}-B y_{k}\right)\right\|^{2}\right)\right] \\
& +\left(\alpha_{k}^{0}-\tau\right) \sum_{i=1}^{p} \alpha_{k}^{i}\left\|U_{i}\left(w_{k}\right)-w_{k}\right\|^{2}+\beta_{k}\left(1-\beta_{k}-\mu\right) \\
& +\left\|p_{k}-T_{j(k)} p_{k}\right\|^{2} \leq\left(1-t_{k}\right) \Gamma_{k}-\Gamma_{k+1}+t_{k}\left(\left\|x^{*}\right\|^{2}\right. \\
& \left.+\left\|y^{*}\right\|^{2}\right)
\end{aligned}
$$

Now, we will divide the proof into two cases to establish strong convergence.

Case 1. Suppose that there exists $k_{0} \in \mathbb{N}$ such that $\Gamma_{k+1} \leq$ $\Gamma_{k}$ for all $k \geq k_{0}$. In this case, $\lim _{k \rightarrow \infty} \Gamma_{k}$ exists and then $\lim _{k \rightarrow \infty}\left(\Gamma_{k+1}-\Gamma_{k}\right)=0$. Hence, using (71) and the assumptions on $\left\{\alpha_{k}^{0}\right\},\left\{\beta_{k}\right\},\left\{t_{k}\right\}$, and $\left\{\gamma_{k}\right\}$, we obtain

$$
\begin{aligned}
\lim _{k \rightarrow \infty}\left\|p_{k}-T_{j(k)} p_{k}\right\| & =0, \\
\lim _{k \rightarrow \infty}\left\|A x_{k}-B y_{k}\right\| & =0, \\
\lim _{k \rightarrow \infty} \sum_{i=1}^{p} \alpha_{k}^{i}\left\|U_{i}\left(w_{k}\right)-w_{k}\right\|^{2} & =0 .
\end{aligned}
$$

The last equality together with condition (1) implies that

$$
\lim _{k \rightarrow \infty}\left\|U_{i}\left(w_{k}\right)-w_{k}\right\|=0, \quad \forall i \in\{1,2, \ldots, p\} .
$$

From (33) and (73), we have

$$
\begin{aligned}
\left\|u_{k}-x_{k}\right\| & =\gamma_{k}\left\|A^{*}\left(A x_{k}-B y_{k}\right)\right\| \\
& \leq \gamma_{k}\left\|A^{*}\right\|\left\|A x_{k}-B y_{k}\right\| \longrightarrow 0, \\
\left\|v_{k}-y_{k}\right\| & =\gamma_{k}\left\|B^{*}\left(A x_{k}-B y_{k}\right)\right\| \\
& \leq \gamma_{k}\left\|B^{*}\right\|\left\|A x_{k}-B y_{k}\right\| \longrightarrow 0 .
\end{aligned}
$$

Then, from (33), (75), and (76) and condition (3), we obtain

$$
\begin{aligned}
\left\|x_{k+1}-x_{k}\right\| \leq & \alpha_{k}^{0}\left\|w_{k}-x_{k}\right\|+\alpha_{k}^{1}\left\|U_{1}\left(w_{k}\right)-x_{k}\right\|+\cdots \\
& +\alpha_{k}^{p}\left\|U_{p}\left(w_{k}\right)-x_{k}\right\| \\
\leq & \left\|w_{k}-x_{k}\right\|+\alpha_{k}^{1}\left\|U_{1}\left(w_{k}\right)-w_{k}\right\|+\cdots \\
& +\alpha_{k}^{p}\left\|U_{p}\left(w_{k}\right)-w_{k}\right\| \\
\leq & \left\|u_{k}-x_{k}\right\|+t_{k}\left\|u_{k}\right\| \\
& +\alpha_{k}^{1}\left\|U_{1}\left(w_{k}\right)-w_{k}\right\|+\cdots \\
& +\alpha_{k}^{p}\left\|U_{p}\left(w_{k}\right)-w_{k}\right\| \longrightarrow 0
\end{aligned}
$$

which together with (75) implies that

$$
\begin{aligned}
\left\|x_{k}-w_{k}\right\| \leq & \left\|x_{k+1}-x_{k}\right\|+\left\|x_{k+1}-w_{k}\right\| \\
\leq & \left\|x_{k+1}-x_{k}\right\|+\alpha_{k}^{1}\left\|U_{1}\left(w_{k}\right)-w_{k}\right\|+\cdots \\
& \quad+\alpha_{k}^{p}\left\|U_{p}\left(w_{k}\right)-w_{k}\right\| \longrightarrow 0 .
\end{aligned}
$$

It follows from (33), (72), and (77) that

$$
\begin{aligned}
\left\|y_{k+1}-y_{k}\right\| \leq & \left(1-\beta_{k}\right)\left\|p_{k}-y_{k}\right\| \\
& +\beta_{k}\left\|T_{j(k)}\left(p_{k}\right)-y_{k}\right\| \\
\leq & \left(1-\beta_{k}\right)\left\|p_{k}-y_{k}\right\| \\
& \quad+\beta_{k}\left\|T_{j(k)}\left(p_{k}\right)-y_{k}\right\| \\
\leq & \left\|p_{k}-y_{k}\right\|+\beta_{k}\left\|T_{j(k)}\left(p_{k}\right)-p_{k}\right\| \\
\leq & \left\|v_{k}-y_{k}\right\|+t_{k}\left\|v_{k}\right\| \\
& +\beta_{k}\left\|T_{j(k)}\left(p_{k}\right)-p_{k}\right\| \longrightarrow 0 .
\end{aligned}
$$

This, combined with (72), yields

$$
\begin{aligned}
\left\|y_{k}-p_{k}\right\| & \leq\left\|y_{k+1}-y_{k}\right\|+\left\|y_{k+1}-p_{k}\right\| \\
& \leq\left\|y_{k+1}-y_{k}\right\|+\beta_{k}\left\|T_{j(k)}\left(p_{k}\right)-p_{k}\right\| \longrightarrow 0 .
\end{aligned}
$$

Since $\left\{\left(x_{k}, y_{k}\right)\right\}$ is bounded in $H^{*}, \omega_{w}\left(x_{k}, y_{k}\right) \neq \emptyset$ and moreover

$$
\omega_{w}\left(x_{k}, y_{k}\right) \subset \Omega .
$$

Indeed, for any $(\hat{x}, \hat{y}) \in \omega_{w}\left(x_{k}, y_{k}\right)$, hence $\hat{x} \in \omega_{w}\left(x_{k}\right)$, $\hat{y} \in \omega_{w}\left(y_{k}\right)$ by virtue of (28). Since $\hat{x} \in \omega_{w}\left(w_{k}\right)$ by (79), it immediately follows from (75) and Assumption 17(iii) that $\hat{x} \in \bigcap_{i=1}^{p} F\left(U_{i}\right)$. On the other hand, since $\left\|y_{k+1}-y_{k}\right\| \rightarrow 0$, now we use Lemma 19 to derive that, for any $j \in\{1,2, \ldots, q\}$, there exists a subsequence $\left\{y_{k_{m}}\right\} \subset\left\{y_{k}\right\}$ such that $y_{k_{m}} \rightarrow \widehat{y}$ and $j\left(k_{m}\right)=j$ for all $m \geq 1$. From (81), it results that $p_{k_{m}} \rightarrow \widehat{y}$. From (72), we have

$$
\lim _{m \rightarrow \infty}\left\|p_{k_{m}}-T_{j} p_{k_{m}}\right\|=\lim _{m \rightarrow \infty}\left\|p_{k_{m}}-T_{j\left(k_{m}\right)} p_{k_{m}}\right\|=0 .
$$

Hence, it follows from (iii) of Assumption 17 that $T_{j} \hat{y}=\hat{y}$ for any $j \in\{1,2, \ldots, q\}$; that is, $\hat{y} \in \bigcap_{j=1}^{q} F\left(T_{j}\right)$. Mimicking the idea in the proof of Theorem 20, we conclude that $A \widehat{x}=B \widehat{y}$; hence, $(\widehat{x}, \widehat{y}) \in \Omega$.

By (33), we observe

$$
\begin{aligned}
\left\|w_{k}-x^{*}\right\|^{2}= & \left\|\left(1-t_{k}\right)\left(u_{k}-x^{*}\right)-t_{k} x^{*}\right\|^{2} \\
= & \left(1-t_{k}\right)^{2}\left\|u_{k}-x^{*}\right\|^{2}+t_{k}^{2}\left\|x^{*}\right\|^{2} \\
& -2 t_{k}\left(1-t_{k}\right)\left\langle u_{k}-x^{*}, x^{*}\right\rangle \\
\leq & \left(1-t_{k}\right)\left\|u_{k}-x^{*}\right\|^{2}+t_{k}^{2}\left\|x^{*}\right\|^{2} \\
& -2 t_{k}\left(1-t_{k}\right)\left\langle u_{k}-x^{*}, x^{*}\right\rangle .
\end{aligned}
$$


Similarly, we have

$$
\begin{aligned}
\left\|p_{k}-y^{*}\right\|^{2} \leq & \left(1-t_{k}\right)\left\|v_{k}-y^{*}\right\|^{2}+t_{k}^{2}\left\|y^{*}\right\|^{2} \\
& -2 t_{k}\left(1-t_{k}\right)\left\langle v_{k}-y^{*}, y^{*}\right\rangle .
\end{aligned}
$$

Then, from (42), (63), (64), (84), and (85), it follows that

$$
\begin{aligned}
& \left\|x_{k+1}-x^{*}\right\|^{2}+\left\|y_{k+1}-y^{*}\right\|^{2} \leq\left\|w_{k}-x^{*}\right\|^{2}+\| p_{k} \\
& -y^{*} \|^{2} \leq\left(1-t_{k}\right)\left(\left\|u_{k}-x^{*}\right\|^{2}+\left\|v_{k}-y^{*}\right\|^{2}\right) \\
& +t_{k}\left[t_{k}\left(\left\|x^{*}\right\|^{2}+\left\|y^{*}\right\|^{2}\right)\right. \\
& \left.+2\left(1-t_{k}\right)\left(\left\langle u_{k}-x^{*},-x^{*}\right\rangle+\left\langle v_{k}-y^{*},-y^{*}\right\rangle\right)\right] \\
& \quad \leq\left(1-t_{k}\right)\left(\left\|x_{k}-x^{*}\right\|^{2}+\left\|y_{k}-y^{*}\right\|^{2}\right) \\
& +t_{k}\left[t_{k}\left(\left\|x^{*}\right\|^{2}+\left\|y^{*}\right\|^{2}\right)\right. \\
& \left.+2\left(1-t_{k}\right)\left(\left\langle u_{k}-x^{*},-x^{*}\right\rangle+\left\langle v_{k}-y^{*},-y^{*}\right\rangle\right)\right] .
\end{aligned}
$$

By the boundedness of $\left\{\left(u_{k}, v_{k}\right)\right\}$ in $H^{*}$, there exists a point $(p, q) \in H^{*}$ and a subsequence $\left\{\left(u_{k_{j}}, v_{k_{j}}\right)\right\}$ of $\left\{\left(u_{k}, v_{k}\right)\right\}$ in $H^{*}$ such that $\left(u_{k_{j}}, v_{k_{j}}\right) \rightarrow(p, q)$ and

$$
\begin{aligned}
& \limsup _{k \rightarrow \infty}\left[\left\langle u_{k}-x^{*},-x^{*}\right\rangle+\left\langle v_{k}-y^{*},-y^{*}\right\rangle\right] \\
& \quad=\lim _{j \rightarrow \infty}\left[\left\langle u_{k_{j}}-x^{*},-x^{*}\right\rangle+\left\langle v_{k_{j}}-y^{*},-y^{*}\right\rangle\right] .
\end{aligned}
$$

Then, it immediately follows from (76), (77), and (82) that $(p, q) \in \omega_{w}\left(u_{k}, v_{k}\right)=\omega_{w}\left(x_{k}, y_{k}\right) \subset \Omega$. Thus, $\left(u_{k_{j}}, v_{k_{j}}\right) \rightarrow$ $(p, q)$ and (87) and (62) yield

$$
\begin{aligned}
& \limsup _{k \rightarrow \infty}\left[\left\langle u_{k}-x^{*},-x^{*}\right\rangle+\left\langle v_{k}-y^{*},-y^{*}\right\rangle\right] \\
& \quad=\lim _{j \rightarrow \infty}\left[\left\langle u_{k_{j}}-x^{*},-x^{*}\right\rangle+\left\langle v_{k_{i}}-y^{*},-y^{*}\right\rangle\right] \\
& =\lim _{j \rightarrow \infty}\left\langle\left(u_{k_{j}}, v_{k_{j}}\right)-\left(x^{*}, y^{*}\right),-\left(x^{*}, y^{*}\right)\right\rangle \\
& =\left\langle(p, q)-\left(x^{*}, y^{*}\right),-\left(x^{*}, y^{*}\right)\right\rangle \leq 0 .
\end{aligned}
$$

Letting $\lambda_{k}=t_{k}, \delta_{k}=2\left(1-t_{k}\right)\left(\left\langle u_{k}-x^{*},-x^{*}\right\rangle+\left\langle v_{k}-y^{*},-y^{*}\right\rangle\right)+$ $t_{k}\left(\left\|x^{*}\right\|^{2}+\left\|y^{*}\right\|^{2}\right)$. From Lemma 13, (86) and (88), and the assumptions on $\left\{t_{k}\right\}$, we conclude that the sequence $\left\{\left(x_{k}, y_{k}\right)\right\}$ converges strongly to $\left(x^{*}, y^{*}\right)$.

Case 2. Suppose that there exists a subsequence $\left\{\Gamma_{k_{i}}\right\} \subset\left\{\Gamma_{k}\right\}$ such that $\Gamma_{k_{i}}<\Gamma_{k_{i}+1}$ for all $i \in \mathbb{N}$. In this case, let $\tau: \mathbb{N} \rightarrow \mathbb{N}$ be a mapping for all $n \geq n_{0}$ (for some $n_{0}$ large enough) by

$$
\tau(n)=\max \left\{k \leq n: \Gamma_{k}<\Gamma_{k+1}\right\} .
$$

Then, we have from Lemma 12 that $\Gamma_{\tau(n)} \leq \Gamma_{\tau(n)+1}$ and, clearly, $\{\tau(n)\}$ is a nondecreasing sequence such that $\tau(n) \rightarrow \infty$ as $n \rightarrow \infty$. From (71), we obtain

$$
\begin{aligned}
& \left(1-t_{\tau(n)}\right) \gamma_{\tau(n)}\left[2\left\|A x_{\tau(n)}-B y_{\tau(n)}\right\|^{2}\right. \\
& \quad-\gamma_{\tau(n)}\left(\left\|A^{*}\left(A x_{\tau(n)}-B y_{\tau(n)}\right)\right\|^{2}\right. \\
& \left.\left.+\left\|B^{*}\left(A x_{\tau(n)}-B y_{\tau(n)}\right)\right\|^{2}\right)\right]+\left(\alpha_{\tau(n)}^{0}-\tau\right) \sum_{i=1}^{p} \alpha_{\tau(n)}^{i} \\
& +\left\|U_{i}\left(w_{\tau(n)}\right)-w_{\tau(n)}\right\|^{2}+\beta_{\tau(n)}\left(1-\beta_{\tau(n)}-\mu\right) \| p_{\tau(n)} \\
& \quad-T_{j(\tau(n))} p_{\tau(n)} \|^{2} \leq\left(1-t_{\tau(n)}\right) \Gamma_{\tau(n)}-\Gamma_{\tau(n)+1} \\
& +t_{\tau(n)}\left(\left\|x^{*}\right\|^{2}+\left\|y^{*}\right\|^{2}\right) \leq t_{\tau(n)}\left(\left\|x^{*}\right\|^{2}+\left\|y^{*}\right\|^{2}\right) \\
& \quad \longrightarrow 0 .
\end{aligned}
$$

Conditions (1)-(3) imply

$$
\begin{aligned}
& \lim _{k \rightarrow \infty}\left\|p_{\tau(n)}-T_{j(\tau(n))} p_{\tau(n)}\right\|=\lim _{k \rightarrow \infty}\left\|A x_{\tau(n)}-B y_{\tau(n)}\right\| \\
& \quad=0,
\end{aligned}
$$

$$
\lim _{k \rightarrow \infty}\left\|U_{i}\left(w_{\tau(n)}\right)-w_{\tau(n)}\right\|=0, \quad(i=1,2, \ldots, p) .
$$

Now, using the sequence $\left\{\left(u_{\tau(n)}, v_{\tau(n)}\right)\right\}$ in place of the bounded sequence $\left\{\left(u_{k}, v_{k}\right)\right\}$ in $H^{*}$ and mimicking the proof of Case 1, we could obtain that

$$
\limsup _{n \rightarrow \infty}\left[\left\langle u_{\tau(n)}-x^{*},-x^{*}\right\rangle+\left\langle v_{\tau(n)}-y^{*},-y^{*}\right\rangle\right] \leq 0 .
$$

With the help of (86) and $\Gamma_{\mathcal{\tau}(n)} \leq \Gamma_{\mathcal{\tau}(n)+1}$, we obtain

$$
\begin{aligned}
0 \leq & \Gamma_{\tau(n)+1}-\Gamma_{\tau(n)} \leq-t_{\tau(n)} \Gamma_{\tau(n)} \\
& +t_{\tau(n)}\left[t_{\tau(n)}\left(\left\|x^{*}\right\|^{2}+\left\|y^{*}\right\|^{2}\right)+2\left(1-t_{\tau(n)}\right)\right. \\
& \left.\cdot\left(\left\langle u_{\tau(n)}-x^{*},-x^{*}\right\rangle+\left\langle v_{\tau(n)}-y^{*},-y^{*}\right\rangle\right)\right],
\end{aligned}
$$

which implies that

$$
\begin{gathered}
\Gamma_{\tau(n)} \leq t_{\tau(n)}\left(\left\|x^{*}\right\|^{2}+\left\|y^{*}\right\|^{2}\right)+2\left(1-t_{\tau(n)}\right) \\
\cdot\left(\left\langle u_{\tau(n)}-x^{*},-x^{*}\right\rangle+\left\langle v_{\tau(n)}-y^{*},-y^{*}\right\rangle\right) .
\end{gathered}
$$

Therefore, from $\lim _{n \rightarrow \infty} t_{\tau(n)}=0$, (92), and the above inequality, we have

$$
\begin{aligned}
0 & \leq \liminf _{n \rightarrow \infty} \Gamma_{\tau(n)} \leq \limsup _{n \rightarrow \infty} \Gamma_{\tau(n)} \leq 0 \Longrightarrow \lim _{n \rightarrow \infty} \Gamma_{\tau(n)} \\
& =0
\end{aligned}
$$

In view of (93), it also results that

$$
\lim _{n \rightarrow \infty} \Gamma_{\tau(n)}=\lim _{n \rightarrow \infty} \Gamma_{\tau(n)+1}=0 .
$$

As a direct consequence of Lemma 12, we have

$$
\Gamma_{n} \leq \Gamma_{\tau(n)+1} \longrightarrow 0 \text {. }
$$


Since $\Gamma_{k}=\left\|x_{k}-x^{*}\right\|^{2}+\left\|y_{k}-y^{*}\right\|^{2}$, the sequence $\left\{\left(x_{k}, y_{k}\right)\right\}$ generated by Algorithm 15 converges strongly to $\left(x^{*}, y^{*}\right)$, completing the proof.

First, we shall give an example which satisfies all the conditions of the solution set $\Omega$ of MSECFP (6) and the mappings $\left\{U_{i}\right\}_{i=1}^{p}$ and $\left\{T_{i}\right\}_{i=1}^{q}$ in Theorems 20 and 21 .

Example 22. Let $H_{1}=H_{2}=H_{3}=\ell_{2}$ and let $i \in\{1,2, \ldots, p\}$ and $j \in\{1,2, \ldots, q\}$ be arbitrarily fixed. Let $U_{i}, T_{j}: \ell_{2} \rightarrow \ell_{2}$ be defined by $U_{i} x=-2 i x$ and $T_{j} x=-(2 j+1) x$ for all $x \in \ell_{2}$. Then, it is easy to see that $\bigcap_{i=1}^{p} F\left(U_{i}\right)=\{0\}=\bigcap_{j=1}^{q} F\left(T_{j}\right)$ and $A 0=0=B 0$. Thus, $\Omega=\{(0,0)\} \neq \emptyset$. Also, $U_{i}$ is $\tau_{i^{-}}$ demicontractive and $T_{j}$ is $\mu_{j}$-demicontractive by Example 2.5 in [9], where $\tau_{i}=(2 i-1) /(2 i+1)$ and $\mu_{j}=j /(j+1)$; then, $I-U_{i}$ and $I-T_{j}$ are demiclosed at 0 by Remark 2.1 in [9].

Next, we give an example which satisfies condition (a) in Theorem 20 and condition (1) in Theorem 21.

Example 23. We can take $\alpha_{k}^{0}=\tau+(1-\tau) /(p+1)+(1-\tau) /(p+$ 2) $(k+1), \alpha_{k}^{1}=\alpha_{k}^{2}=\cdots=\alpha_{k}^{p}=(1-\tau) /(p+1)-(1-\tau) / p(p+$ 2) $(k+1)(k \geq 0)$.

Remark 24. The following two mistakes in the proof of Theorem 3.2 in [9] should be modified as in the proof of Theorem 21:

(i) In Case 1, the part "for any $\widehat{x} \in \omega_{w}\left(x_{k}\right)$ and $\hat{y} \in$ $\omega_{w}\left(y_{k}\right)$ " and in Case 2 the part "for any $\bar{x} \in \omega_{w}\left(x_{\tau(n)}\right)$ and $\bar{y} \in \omega_{w}\left(y_{\tau(n)}\right)$ " should be modified to "for any $(\hat{x}, \hat{y}) \in \omega_{w}\left(x_{k}, y_{k}\right)$ " and "for any $(\bar{x}, \bar{y}) \in$ $\omega_{w}\left(x_{\tau(n)}, y_{\tau(n)}\right), "$ respectively.

(ii) For proving (3.21) of Theorem 3.2 in [9], we should adopt the proving method of (87) and (88) in Theorem 21.

Remark 25. We can also consider the following two algorithms:

$$
\begin{aligned}
u_{k} & =x_{k}-\gamma_{k} A^{*}\left(A x_{k}-B y_{k}\right), \\
x_{k+1} & =\left(1-\alpha_{k}\right) u_{k}+\alpha_{k} U_{i(k)}\left(u_{k}\right), \\
v_{k} & =y_{k}+\gamma_{k} B^{*}\left(A x_{k}-B y_{k}\right), \\
y_{k+1} & =\beta_{k}^{0} v_{k}+\beta_{k}^{1} T_{1}\left(v_{k}\right)+\cdots+\beta_{k}^{q} T_{q}\left(v_{k}\right)
\end{aligned}
$$

and

$$
\begin{aligned}
u_{k} & =x_{k}-\gamma_{k} A^{*}\left(A x_{k}-B y_{k}\right), \\
w_{k} & =\left(1-t_{k}\right) u_{k}, \\
x_{k+1} & =\left(1-\alpha_{k}\right) w_{k}+\alpha_{k} U_{i(k)}\left(w_{k}\right), \\
v_{k} & =y_{k}+\gamma_{k} B^{*}\left(A x_{k}-B y_{k}\right), \\
p_{k} & =\left(1-t_{k}\right) v_{k}, \\
y_{k+1} & =\beta_{k}^{0} p_{k}+\beta_{k}^{1} T_{1}\left(p_{k}\right)+\cdots+\beta_{k}^{q} T_{q}\left(p_{k}\right) .
\end{aligned}
$$

Under the suitable conditions, using methods similar to Theorems 20 and 21, we can prove the weak and strong convergence of the sequences $\left\{\left(x_{k}, y_{k}\right)\right\}$ generated by these two algorithms, respectively.

\section{Conflicts of Interest}

The authors declare that they have no conflicts of interest.

\section{Acknowledgments}

Tae-Hwa Kim is supported by a research grant from Pukyong National University (year 2017). Yaqin Wang is supported by the National Natural Science Foundation of China (nos. 11401388 and 11671365). Xiaoli Fang is supported by Zhejiang Provincial Natural Science Foundation of China (nos. LQ13A010007 and LY14A010006).

\section{References}

[1] Y. Censor and T. Elfving, "A multiprojection algorithm using Bregman projections in a product space," Numerical Algorithms, vol. 8, no. 2-4, pp. 221-239, 1994.

[2] C. Byrne, "Iterative oblique projection onto convex sets and the split feasibility problem," Inverse Problems, vol. 18, no. 2, pp. 441453, 2002.

[3] Y. Yao, R. P. Agarwal, M. Postolache, and Y.-C. Liou, "Algorithms with strong convergence for the split common solution of the feasibility problem and fixed point problem," Fixed Point Theory and Applications, vol. 2014, no. 1, article no. 183, 14 pages, 2014.

[4] Y. Yao, M. Postolache, and Y.-C. Liou, "Strong convergence of a self-adaptive method for the split feasibility problem," Fixed Point Theory and Applications, vol. 2013, article no. 201, 12 pages, 2013.

[5] Y. Yao, W. Jigang, and Y.-C. Liou, "Regularized methods for the split feasibility problem," Abstract and Applied Analysis, vol. 2012, Article ID 140679, 13 pages, 2012.

[6] A. Moudafi and E. Al-Shemas, "Simultaneous iterative methods for split equality problem," Transactions on Mathematical Programming and Applications, vol. 1, no. 2, pp. 1-11, 2013.

[7] J. Zhao, "Solving split equality fixed-point problem of quasinonexpansive mappings without prior knowledge of operators norms," Optimization. A Journal of Mathematical Programming and Operations Research, vol. 64, no. 12, pp. 2619-2630, 2015.

[8] J. Zhao and S. Wang, "Mixed iterative algorithms for the multiple-set split equality common fixed-point problems without prior knowledge of operator norms," Optimization. A Journal of Mathematical Programming and Operations Research, vol. 65, no. 5, pp. 1069-1083, 2016.

[9] Y. Wang and T. H. Kim, "Simultaneous iterative algorithm for the split equality fixed-point problem of demicontractive mappings," Journal of Nonlinear Sciences and Applications, vol. 10, no. 1, pp. 154-165, 2017.

[10] W. Takahashi, Nonlinear Functional Analysis, Yokohama Publishers, Yokohama, Japan, 2000.

[11] G. Marino and H.-K. Xu, "Weak and strong convergence theorems for strict pseudo-contractions in Hilbert spaces," Journal of Mathematical Analysis and Applications, vol. 329, no. 1, pp. 336-346, 2007. 
[12] Y. Censor and A. Segal, "The split common fixed point problem for directed operators," Journal of Convex Analysis, vol. 16, no. 2, pp. 587-600, 2009.

[13] K. Goebel and W. A. Kirk, Topics in Metric Fixed Point Theory, vol. 28 of Cambridge Studies in Advanced Mathematics, Cambridge University Press, Cambridge, UK, 1990.

[14] C. Martinez-Yanes and H.-K. Xu, "Strong convergence of the CQ method for fixed point iteration processes," Nonlinear Analysis. Theory, Methods \& Applications. An International Multidisciplinary Journal, vol. 64, no. 11, pp. 2400-2411, 2006.

[15] A. Moudafi, "The split common fixed-point problem for demicontractive mappings," Inverse Problems, vol. 26, no. 5, Article ID 055007, pp. 587-600, 2010.

[16] M. C. Joshi and R. K. Bose, Some topics in nonlinear functional analysis, John Wiley and Sons, New York, NY, USA, 1985.

[17] P. L. Combettes, Fejér-Monotonicity in Convex Optimization, in Encyclopedia of Optimization, C. A. Floudas and P. M. Pardalos, Eds., vol. 2, Springer-Verlag, New York, NY, USA, 2001.

[18] S.-W. Han and T.-H. Kim, " $\phi$-Fejér-monotone sequences and their convergence theorems," Journal of Nonlinear and Convex Analysis, vol. 17, no. 2, pp. 211-223, 2016.

[19] P.-E. Maingé, "Strong convergence of projected subgradient methods for nonsmooth and nonstrictly convex minimization," Set-Valued and Variational Analysis, vol. 16, no. 7-8, pp. 899-912, 2008.

[20] H.-K. Xu, "Iterative algorithms for nonlinear operators," Journal Of The London Mathematical Society-Second Series, vol. 66, no. 1, pp. 240-256, 2002.

[21] Y. Wang, T.-H. Kim, X. Fang, and H. He, "The split common fixed-point problem for demicontractive mappings and quasinonexpansive mappings," Journal of Nonlinear Sciences and Applications, vol. 10, no. 6, pp. 2976-2985, 2017. 


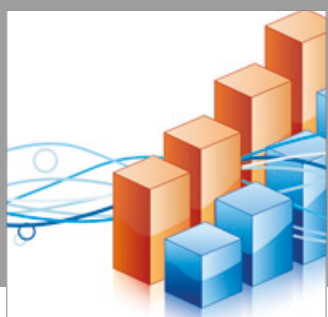

Advances in

Operations Research

vatersals

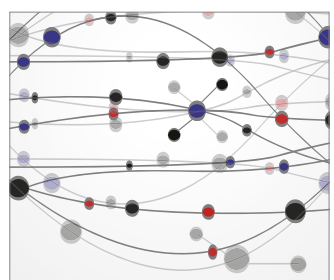

\section{The Scientific} World Journal
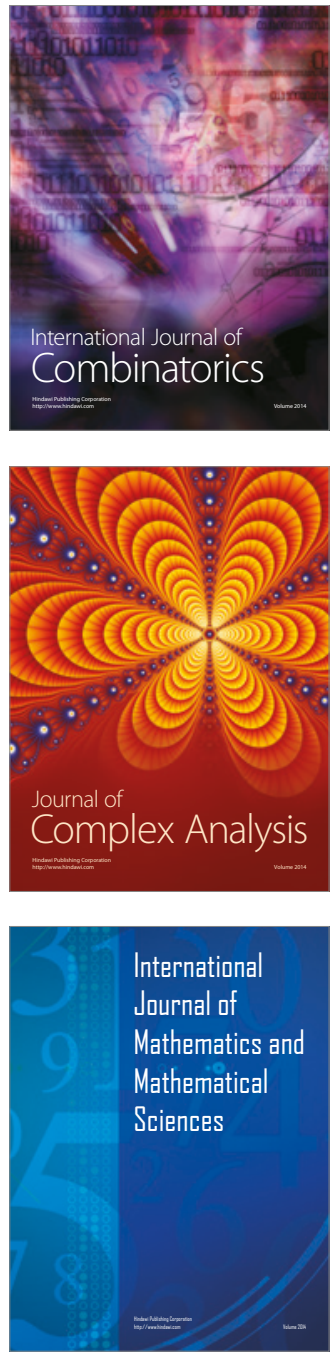
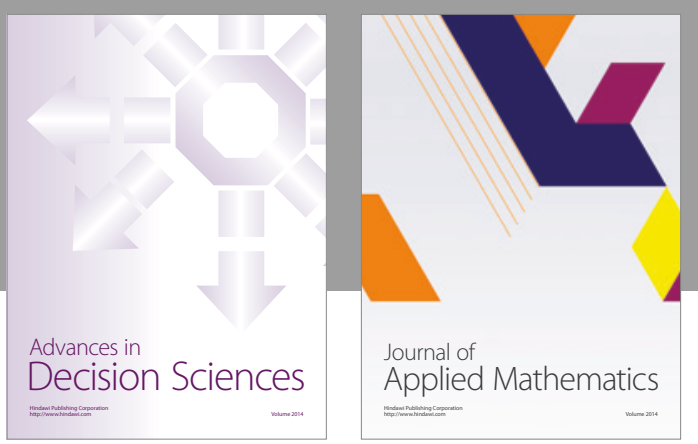

Algebra

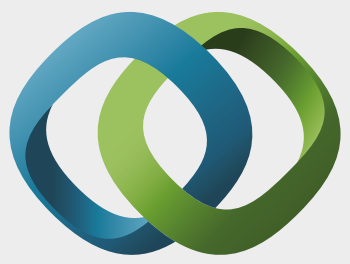

\section{Hindawi}

Submit your manuscripts at

https://www.hindawi.com
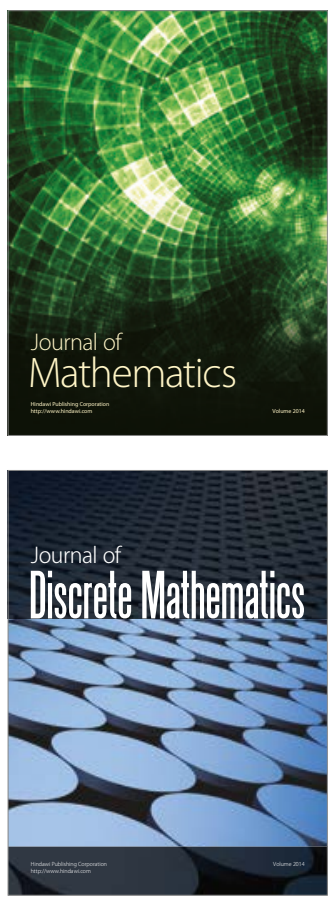

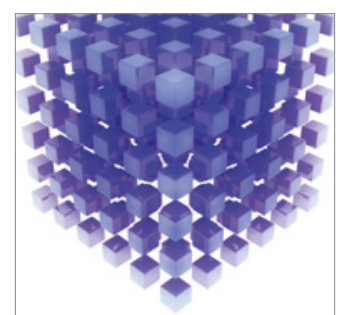

Mathematical Problems in Engineering
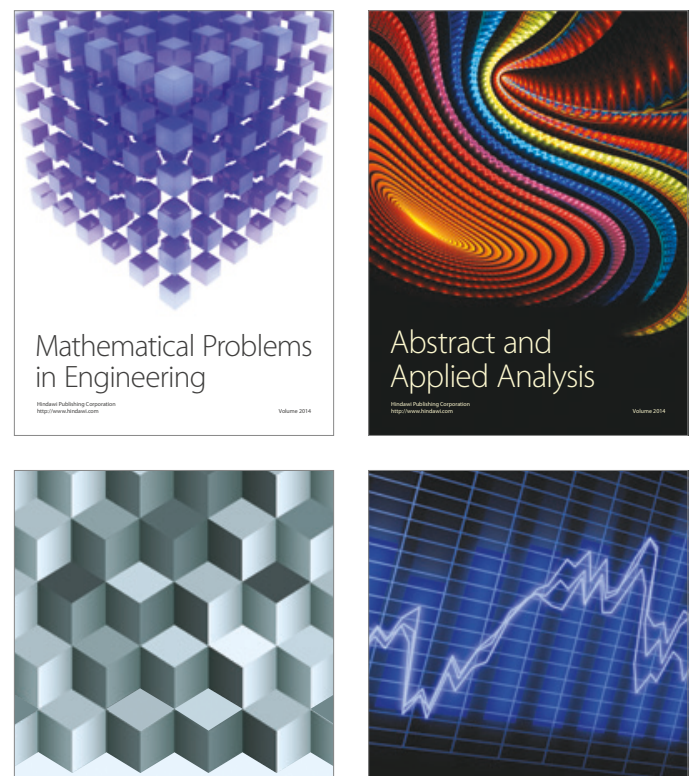

Journal of

Function Spaces

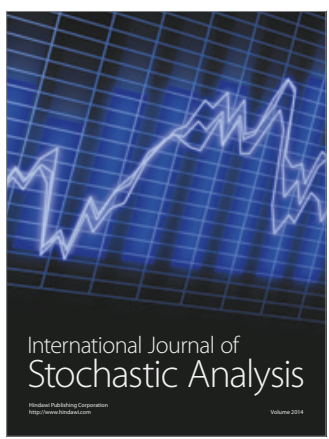

Probability and Statistics
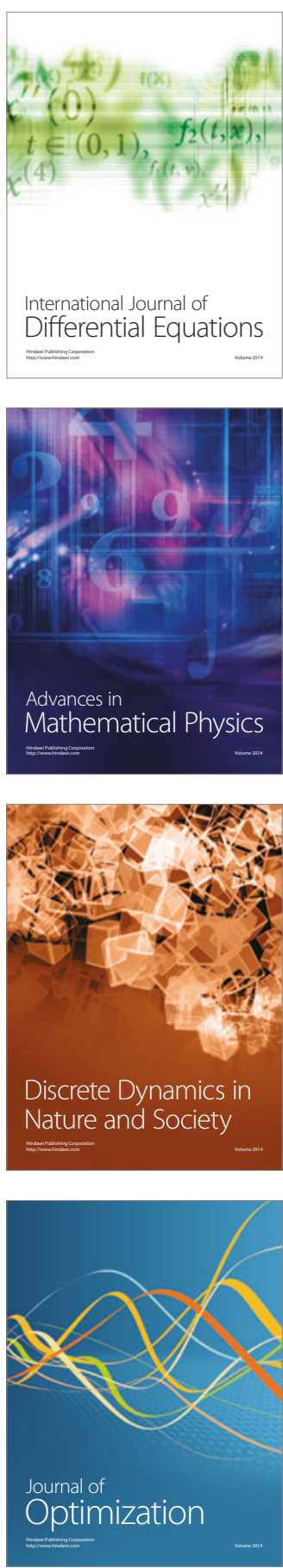